\title{
TRIGGERING INSPECTIONS EX OFFICIO: MOVING BEYOND A PASSIVE EU CARTEL POLICY
}

\author{
Hans W. Friederiszick* E Frank P. Maier-Rigaud**
}

\begin{abstract}
The implementation of leniency programs is considered a success both at a EU Community level and in individual member states. The paper discusses the value of ex officio investigations for cartel detection in light of leniency and complaint-based cases. Are ex officio investigations still needed? Should a competition authority concentrate its scarce resources exclusively on the prosecution of leniency or complaint-based cases or follow a proactive market monitoring policy? It is argued that investigations triggered ex officio are an important complementary enforcement tool to the other passive instruments available to a competition authority. A bottom-up methodology for triggering inspections based on economic criteria is presented allowing for a more proactive cartel policy.
\end{abstract}

\section{INTRODUCTION}

This paper presents an overview of an economic methodology for triggering inspections in cartel cases currently being developed within the European Commission. The overarching objective of antitrust policy in the context of cartels is the deterrence and desistence of collusive agreements. The possibility of modifying the incentives to collude and the success of the leniency programs (see Riley, 2005) in triggering applications have led competition authorities throughout the world to shift resources to the prosecution of leniency cases. In the period from $2002^{1}$ to the end of 2005, the Commission adopted 30

\footnotetext{
* European Commission, Directorate General Competition, Chief Economist Team, Brussels, Belgium. E-mail: friederiszick@esmt.org. Since October 2006, his new affiliation is the European School of Management and Technology (ESMT), Berlin. We thank Svend Albæk, Rainer Becker, Joe Harrington, Massimo Motta, Marc Pirrung, Lars-Hendrik Röller, Pierluigi Sabbattini, Andreas Seip, Maarten Pieter Schinkel, Daniel Wiesen, three anonymous referees, and participants at the ACLE Forensic Economics Conference in Amsterdam, the European Competition Network Chief Economist meeting, the 25th Conference on Political Economy in Saarbrücken, and our colleagues from DG Competition. The views expressed are those of the authors and not of the European Commission.

** European Commission, Directorate General Competition, Directorate A, Policy and Strategic Support, Brussels, Belgium; Department of Economics, University of Bonn and Max Planck Institute for Research on Collective Goods, Bonn, Germany. E-mail: maier-rigaud@, microeconomics.de.

${ }^{1}$ In 2002, the Commission Notice on Immunity from Fines and Reduction of Fines in Cartel Cases, OJ C45/3, February 19, 2002, went into force replacing the first leniency program instituted by the Commission in 1996. In the six years in which the first leniency program applied,
} 
statements of objections, a necessary procedural step before taking a decision in cartel cases, roughly two-thirds of which were based on leniency applications. Based on these recent successes, the value of proactive ex officio cartel screens for the leniency program and for cartel policy in general are discussed. The paper is structured in the following way. Section II provides an introduction to the nature of collusion and the role of economics. Section III discusses the legal basis and the enforcement instruments available to the Commission for fighting cartels. Section IV discusses the interdependency and the individual advantages of leniency, complaint-based, and ex officio cartel detection. Section $\mathrm{V}$ discusses the two main types of methodologies for cartel detection based on economic criteria-bottom-up and top-down approaches. Section VI introduces the two-step methodology and Section VII concludes.

\section{THE NATURE OF COLLUSION AND THE ROLE OF ECONOMICS}

From an economic point of view, collusion describes a situation where market prices are close to monopoly prices despite an oligopolistic market structure. In contrast to unilateral conduct, which also may allow prices to rise significantly above the competitive price level in an oligopolistic environment, collusion rests on the dynamic interaction between firms: firms condition their future behavior in the market on the current behavior of competitors. For instance, firms may revert to 'cut throat competition' for some period in the future in reaction to a competitor's deviation from collusive price levels. This type of dynamic interaction allows firms to maintain prices at levels close to monopoly prices and significantly above what unilateral conduct alone would allow.

Consider a simple symmetric duopoly situation where the two firms $i$ and $j$ can choose to compete or collude. Table 1 presents the situation in a typical 2-firm matrix game where the first value in brackets represents the payoff of firm $i$ and the second the payoff of firm $j$. If profits are ranked in the following way, $a>b>c>d$, the game is a classic prisoner's dilemma (PD) game. ${ }^{2}$

In a simple one-period setting, collusion does not constitute a Nash equilibrium and rational firms will therefore never collude under perfect information. Two firms will only collude if the cartel internal incentive constraint is not violated, that is, if the (expected) profits of collusion are higher than the (expected) profits of defection, $\pi_{\text {col }} \geq \pi_{\text {def }}$. By assumption, the incentive

the Commission received more than 80 applications, although the number of applications has since 2002 risen to 165 in less than four years. See p. 56 in European Commission (2006).

2 A second condition, $2 b>a+d>2 c$, is required to ensure that collusion remains the most attractive strategy for both players in a repeated context and that a strategy alternating between collude/compete and compete/collude does not result in higher profits (see Rappoport and Chammah (1966)). 
Table 1. General $2 \times 2$ prisoner's dilemma game

\begin{tabular}{lll}
\hline & Collude & Compete \\
\hline Collude & $(\mathrm{b}, \mathrm{b})$ & $(\mathrm{d}, \mathrm{a})$ \\
Compete & $(\mathrm{a}, \mathrm{d})$ & $(\mathrm{c}, \mathrm{c})$ \\
\hline
\end{tabular}

constraint is violated in the one-shot game: the defection profit in the one-shot case, $a$, is larger than $b$, representing profits under collusion. Hence, firms will fall back to the unilateral output or price levels and the competitive equilibrium emerges. ${ }^{3}$ Introducing time into the game, that is, periods are indexed by $t \in\{0,1,2, \ldots, T\}$, other outcomes may become equilibrium outcomes.

One possibility is to transform the one-shot game into a supergame by repeating the stage game depicted in Table 1 infinitely (formally $T \rightarrow \infty$ ). In the simplest scenario without discounting of future payoffs, the folk theorem applies, indicating that an infinite number of strategies can be supported as equilibria. Introducing a discount factor, $\delta \in(0,1)$, collusion remains a sustainable strategy if firms find it more profitable to adhere to the cartel than to defect. Formally, the incentive constraints are

$$
\sum_{t=0}^{\infty} \delta^{t} b=\frac{1}{1-\delta} b \geq a+\sum_{t=1}^{\infty} \delta^{t} c=a+\frac{\delta}{1-\delta} c
$$

that is, expected profits of collusion (left-hand side of the inequality) are greater (or equal) than expected profits of defection (right-hand side of the inequality). ${ }^{4}$ In the absence of competition policy, this incentive constraint describes the logic of cartel dynamics. ${ }^{5}$ Holding profits, that is, market conditions, constant it is possible to solve for the critical discount factor for

${ }^{3}$ Note that Cournot (where strategies are in quantities) or Bertrand (where strategies are in prices) games can be reduced to a prisoner's dilemma game by restricting the set of players and actions to two. For example, in such a setting, $2 b$ would correspond to the monopoly profit feasible under the assumption of quantity, respective price, competition. For the purpose of this paper, it is therefore unnecessary to extend the analysis to complex scenarios as all the points can also be made based on a symmetric PD game. Note, however, that a structural dynamic approach may allow to describe the emergence and breakdown of cartels.

${ }^{4}$ For the case of a Cournot oligopoly, Friedman (1971) has shown that a grim trigger strategy, that is, choose the collusive output until one firm deviates and produce the competitive output thereafter, although not renegotiation proof, allows to sustain collusion for a range of discount factors. Note that this type of Nash reversion is typically not optimal with continuous strategy spaces and an arbitrary restriction of punishment to Nash reversion may be problematic (Kühn, 2005).

${ }^{5}$ Note that this implies that leniency may still trigger applications even in the absence of detection. The reason for this is that market conditions may change the incentives for collusion and firms will apply for leniency to get a head start in the ensuing competition. 
which the incentives to cooperate equal the incentives to defect, that is,

$$
\delta^{*}=\frac{a-b}{a-c} .
$$

If $\delta \geq \delta^{*}$, that is, the future is relatively important, collusion is stable. Collusion is stable because the threat to revert to the one-shot Nash equilibrium is credible and does not allow any firm to deviate profitably while the collusive outcome is more profitable for both firms. ${ }^{6}$

Although the duopoly scenario outlined above is rather basic and the models are more complicated with $n$ firms, larger strategy spaces (that is, more than a binary choice set), or uncertainty, game theory as such cannot be considered to be particularly helpful for the empirical problem of cartel detection. It allows the possibly infinite amount of collusive equilibria to be identified, but remains silent about the process of equilibrium selection and how firms actually coordinate. ${ }^{7}$

As a result, economic theory can at best help to distinguish between competitive and collusive equilibria and provide some general considerations under what conditions collusion is more likely to arise. ${ }^{8}$ Because some of these considerations will be taken up in the section introducing the methodology for triggering inspections using economic indicators, they are not discussed here. ${ }^{9}$

It may, however, be important to point out at this stage that, despite contrary theoretical predictions, collusion has been continuously found and sustained for long periods of time in the experimental laboratory. ${ }^{10}$ Although it is outside the scope of this paper to discuss this literature, experimental

${ }^{6}$ A second possibility to allow collusion as a potential equilibrium in the PD game is to have the game end in finite but stochastic time by introducing a probability of termination. In that case, the probability of the game ending is 1 , while the final period remains unknown. Such a situation is equivalent to a supergame with lower discount factor, that is, $\delta=\rho \delta$, where $\rho \in(0,1)$ is the probability of continuation. For games that end in finite but nonstochastic time, Luce and Raiffa (1957) have shown that the only subgame perfect equilibrium is both firms competing in all periods. Applying the logic of backward induction, the unique Nash-equilibrium outcome of the finitely repeated PD game under perfect information is again the one in which both firms compete in every single period (see for example, Binmore, 1992; or Osborne and Rubinstein, 1994).

7 See Mehta (2005) or Cabral (2005), who note that subgame perfection may not even be the right equilibrium concept.

${ }^{8}$ In addition to the explicit factors to be mentioned below, the literature has also pointed to more subtle coordinating devices (Scherer and Ross, 1990) that do not require any explicit coordination between firms. The concept of salient strategies, termed focal points, is an example (see Schelling, 1960).

${ }^{9}$ For overviews of the theoretical literature on collusion, see, for instance, Tirole (1988), Shapiro (1989), Motta (2004), Feuerstein (2005), or Ivaldi et al. (2006).

10 See Holt (1995) for an overview, or, for instance, the classic theoretical paper by Selten (1973) and experimental follow-up studies by Huck et al. (2004) analyzing the role the number of firms plays for sustaining collusion. See also Beckenkamp et al. (2007), Engel (2007), and the comprehensive overview by Engel (2006). 
methods may allow a more thorough understanding of what actually is conducive to collusion and what is not. ${ }^{11}$

If one wants to derive economic criteria to detect collusion, a relevant insight is that tacit and explicit collusion rest on the same economic principles. The notion of explicit collusion refers to what is legally considered to be a cartel, that is, a situation where firms directly interact to establish collusion. Tacit collusion in contrast describes a situation where the firms can establish supracompetitive prices without direct interaction. If cartel members cannot write enforceable contracts, the incentive to defect exists equally in both scenarios.

The equivalence of the underlying economics of tacit and explicit collusion means that the criteria established in the context of merger control to identify tacit collusion also provide a meaningful framework for the detection of explicit collusion. More specifically, the following factors have been established in the merger control context to be of relevance. Firms have (i) to reach terms of coordination, (ii) to monitor compliance, (iii) to threaten timely retaliation, and (iv) to limit the reactions by outsiders. ${ }^{12}$

The drawback of the fact that the same economic incentives arise under the two different forms of collusion is that economic indicators are of limited value for distinguishing between the two. This is one of the reasons why economists tend to reject the idea of prosecuting cartels on economic grounds only. ${ }^{13}$

The following section introduces the enforcement instruments available to the Commission and their legal basis.

\section{ENFORCEMENT INSTRUMENTS UNDER EC LAW}

In the practice of the European Commission, cartel detection based on inspections at the premises of firms plays a crucial role. Surprise inspections are by far the most effective and sometimes the only means of obtaining the necessary

11 Note that this is also of crucial importance with respect to collective dominance, where a focus on game theoretical concepts in particular with respect to what can be considered a credible punishment mechanism, may be too narrow for a real world competition assessment.

12 See CFI in case Airtours Plc v Commission, T-342/99, $\$ 62$ or Guidelines on the assessment of horizontal mergers under the Council Regulation on the control of concentrations between undertakings, OJ C31, 05.02.2004, \$41.

13 Motta (2004: 187) and Kühn (2001: 175), for instance, argue against prosecuting tacit collusion under Art. 81 of the Treaty. They provide some examples where it is not possible to distinguish between explicit or tacit collusion based on economic criteria. In addition, both make the point that a case built on economic criteria only will not meet the standard of proof for prosecuting an alleged cartel. Note, however, that Motta is also mentioning a case where it was considered possible to presume explicit collusion despite missing direct evidence. In the Dyestuffs case, the degree of price parallelism reached a level that — as was argued — could only be explained by direct communication. In general, mainstream economics has little to say on tacit collusion and Kühn (2005: 208) notes: "The literature has made virtually no progress on dealing with the issue of tacit collusion. However, this is a crucial issue that needs to be resolved for policy purposes, especially in the context of coordinated effects analysis in merger cases." 
evidence for sanctioning a cartel. Given the generally secret nature of evidence, no real alternative investigative tools currently exist on the European level. The efforts to enforce competition policy in the area of cartels thus crucially hinge on the capability of the Commission to trigger and carry out successful inspections based on a formal decision where the companies concerned are under a legal obligation to submit to the investigation. The legal basis for inspections is found in Regulation $1 / 2003,{ }^{14}$ which specifically grants the Commission the power to "conduct all necessary inspections of undertakings and associations of undertakings" (Art. 20(1)). The firm concerned can challenge the lawfulness of a Commission decision ordering an unannounced inspection (exclusively) before the Court of Justice. A national court may not call into question the necessity for the inspection nor demand that it be provided with the information in the Commission's file.

The initial evidence prompting the Commission to adopt an inspection decision is often provided by cartel members in the context of a leniency application but it may also stem from whistleblowers, that is, former employees that can provide the Commission with insights or even documents about the functioning of the alleged cartel. These channels often rely on more or less direct evidence (witness testimony, meeting notes, correspondence, etc.) on the organization, the duration, and the members of the cartel. It is clear that the Commission is not entitled to "fishing expeditions," that is, to launch intrusive investigative measures in an unfocused attempt in the hope of finding some evidence of cartel activity. There is, however, no reason why more indirect evidence of cartel activity should not be capable of creating a sufficient degree of suspicion to justify an inspection by the Commission. ${ }^{15}$ For instance, customers may observe clear signs of collusive behavior and report these to the Commission. Also indirect and circumstantial evidence based on a sector inquiry ${ }^{16}$ or a market screen, that is, the active assessment of markets by a competition authority according to predefined economic criteria, cannot a priori be ruled out as a potential source for an objectively founded suspicion of a specific cartel. Particularly bottom-up approaches analyzing one specific market in detail as opposed to more aggregate top-down analyses that screen several sectors are promising in this respect. ${ }^{17}$

14 Council Regulation (EC) No 1/2003 of 16 December 2002 on the implementation of the rules on competition laid down in Articles 81 and 82 of the Treaty, OJ L1, 04.01.2003, p. 1. Inspection powers are in particular laid down by Art. 20, Art. 21 for inspection of other than business premises and Art. 22 for investigations carried out by member states at the request of the Commission.

15 Even in the final decision imposing a fine on cartel members, the Commission can use indirect forms of evidence to meet the required standard of proof. The Commission is therefore, $a$ fortiori, clearly able to rely on indirect evidence to demonstrate the objective foundation of an initial suspicion justifying an inspection decision.

16 The Commission undertook inspections in May and December 2006 relying on customer responses in the context of the energy sector inquiry.

17 See Section V for a discussion of these two different approaches. 
EC law does not contain any explicit rule on the exact level of suspicion the Commission needs to have for a decision ordering surprise investigations to be lawful. It would go beyond the scope of the present paper to undertake a comprehensive analysis of this complex legal issue. Nonetheless, some indications can be drawn from Regulation 1/2003 and the case law of the Court of Justice, which provide a good first approximation of the degree of information an economic methodology would have to generate to allow the Commission to adopt a decision ordering surprise investigations.

According to Art. 20(4) of Regulation 1/2003, inspection decisions must explain the subject-matter and the purpose of the inspection, that is, indicate the presumed facts to be investigated. ${ }^{18}$ The suspicion of cartel activity must therefore be sufficiently specific as to enable the Commission to name (i) the behavior in question, (ii) the competition rules violated, and (iii) the (groups of) products or services concerned. Clearly an economic methodology can generate that information and is therefore at least as good as complaints. ${ }^{19}$

Although Art. 20(8) directly relates only to the scrutiny by national courts in certain specific situations, it is clear from this provision and from general principles of Community law $^{20}$ that the investigation decision and any coercive measures envisaged must not be "arbitrary." The Court of Justice clarified that this is the case when "the Commission is in possession of information and evidence providing reasonable grounds for suspecting infringement of competition rules by the undertaking concerned" (emphasis added). ${ }^{21}$ From this it follows, first, that the Court appears to apply a standard of "reasonable suspicion" as a condition for the Commission to adopt an Art. 20(4) investigation decision. This standard is likely to be fulfilled where the information available to the Commission is such that any reasonable person would believe, at the time when the decision was taken, that an infringement of competition rules is a serious possibility. Second, the quoted passage also emphasizes that the information available to the Commission must be sufficiently precise to

18 See ECJ in case C-227/92P Hoechst AG v. Commission [1999], §41, in case C-94/00 Roquette Frères SA v. Directeur général de la concurrence, de la consommation et de la répression des fraudes [2002], $₫ 47$ and $₫ 48$ and in case 136/79 National Panasonic (UK) Limited v. Commission [1980], \26 and $₫ 27$.

19 In fact, information from whistleblowers and complaints, but also information generated in the context of a leniency program, is often incomplete and may be subject to strategic distortions. An economic methodology, in contrast, provides a reassessment of that type of information within a more balanced framework and complements the data with data from independent sources. It thereby limits the danger of a "complainant driven" cartel policy.

20 Cf. Hoechst, $₫ 19$ : “the need for [protection against arbitrary or disproportionate intervention] must be recognized as a general principle of Community law."

21 Roquette Frères (referred to above), \54 and \$61; in French: "l'existence d'indices suffisamment sérieux permettant de suspecter une infraction aux règles de concurrence par l'entreprise concernée"; in German: "ernsthafte Indizien vorliegen, die für den Verdacht eines Verstoßes gegen die Wettbewerbsregeln durch das betroffene Unternehmen ausreichen.” 
allow the identification of each specific firm to be subjected to an inspection ("the undertaking concerned"). Again, bottom-up methodologies clearly have the potential to satisfy these two criteria.

The Court of Justice also pointed out at various occasions that inspections, as any other investigatory measure under Regulation $1 / 2003$ (the previous Regulation 17), have to be "necessary" 22 and must not be "disproportionate." ${ }^{\prime 3}$ These two requirements refer primarily to the choice of the appropriate investigative measure and only indirectly to the degree of information required to justify an inspection decision. The requirements are therefore independent of how the initial information was generated.

Properly conducted bottom-up market screens, such as the methodology presented in Section VI, clearly have the potential to be as effective in meeting the burden of proof as more traditional sources of information and may sometimes even be superior to the latter. ${ }^{24}$ The important role of ex officio cartel screens for competition policy and the interrelationship of this economics-based instrument with other enforcement tools, in particular the leniency program, is discussed in the next section.

\section{DETERRENCE, DESISTENCE, AND DETECTION-ESSENTIAL ELEMENTS OF A PROACTIVE CARTEL POLICY}

The overarching objective of antitrust policy is deterrence and desistence. By influencing factors of internal and external cartel stability, ${ }^{25}$ cartel policy can

${ }^{22}$ Necessity in this context means that the relationship between the information sought and the alleged infringement must be such that the Commission can reasonably suppose, at the time of the investigative measure, that the evidence sought will help it to determine whether the suspected infringement has taken place; cf. ECJ in case C-36/92P Samenwerkende ElektriciteitsProduktiebedrijven (SEP) NV v. Commission [1994] ECR I-1911, \$21 referring to the opinion of Advocate-General Jacobs.

${ }^{23}$ The safeguard against disproportionate investigative measures requires the Commission to consider the impact of the measure in light of the objective pursued, namely the enforcement of competition rules in the public interest. The ECJ held that an inspection decision that is aimed solely at enabling the Commission to collect the necessary information to appraise whether the Treaty has been infringed is not contrary to the principle of proportionality (cf. Case 136/79 National Panasonic (UK) Limited v. Commission [1980] ECR page 2033, IS 28-30; see also case C-94/00 Roquette Frères, \$77). Especially with respect to coercive measures that have recourse to the law-enforcement authorities of the member states, the assessment of proportionality should take into account, inter alia, the seriousness of the suspected infringement, the nature of the involvement of the undertaking concerned, and the importance of the evidence sought (Roquette Frères, referred to above, $\$ 79$ ).

${ }^{24}$ As recognized by Chief Judge Walker, "s $(\mathrm{S})$ tatistical and economic evidence suffers from fewer reliability concerns than speculation by customers, competitors and other market participants (assuming, of course, the soundness of the methodology by which such evidence is derived)." See Walker (2006: 6).

25 Note that there exists an extensive theoretical literature spanning from research on collusive stability as in Green and Porter (1984) to models dealing with leniency, as for instance Motta and Polo $(1999,2003)$ or the recent more general paper by Buccirossi and Spagnolo (2006). For an experimental analysis of leniency, see Apesteguia et al. (2007). 
render the formation of cartels unattractive (deterrence) or can trigger the break-up of existing cartels (desistence). Consider the incentive constraint for collusion discussed in Section II in the context of the infinitely repeated duopoly game. For a given market structure (that is, profits remain as denoted in the game), discount factor, and effectiveness of antitrust enforcement, collusion is either stable or not in a particular industry. From that perspective, an ideal cartel policy modifies the incentive structure of individual firms in such a way that collusion is no longer sustainable. Such a policy suppresses the existence of cartels immediately in the wake of its implementation. Owing to its immediate effect on market cartelization, deterrence and desistence limit the harm to consumers to a minimum. In addition, they minimize the resource requirements of a competition authority as cartel prosecution, which often binds a significant amount of resources of the authority, becomes irrelevant in equilibrium. ${ }^{26}$

In light of the success of the leniency programs in triggering applications, one may ask whether cartel authorities should not refrain from applying and developing proactive detection tools such as market screens based on economic criteria.

In the following, four arguments are put forward in favor of a policy of proactive cartel detection. First, it is argued that if full deterrence cannot be achieved, for instance, due to ineffective instruments, resource constraints of the competition authority or uncertainty ${ }^{27}$ in the market, proactive cartel detection becomes the only tool available to detect cartels outside the reach of the competition authority. Second, it is argued that in some instances leniency is little more than terminal care for cartels, limiting the consumer benefits of cartel detection in those instances. Third, it is established that proactive cartel detection also adds to cartel deterrence. Finally, it is argued that cartel detection and leniency programs exhibit strong complementarities with respect to cartel deterrence.

With respect to the first argument, recall that an ideal cartel policy allows 100 percent cartel deterrence. If, however, cartel policy is subject to constraints in manipulating the expected profits of collusion and/or defection, that is, fines cannot be set to infinity or leniency cannot provide full reductions or rewards, cartels may still be observed. ${ }^{28}$ In such a second-best world,

${ }^{26}$ In practice, desistence under leniency may, however, have resource consequences, as the authority has to deal with the leniency applications and the follow-up.

27 Note for instance that the notion of "over-deterrent fine" only makes sense in a context with uncertainty about what constitutes an infringement and what does not. In the absence of such uncertainty, a fine, $F_{i}$, is either deterrent or not. Typically $F^{*}$, the optimal fine level, is chosen such that $F^{*}=$ net cartel profit (or net consumer harm) $\times$ inverse of the detection probability, but any $F_{i}>F^{*}$, that is, $F_{i} \rightarrow \infty$ provides "optimal" deterrence. With such a fine, no infringement is committed in equilibrium and consequently no fine is ever paid.

${ }^{28}$ Further, probably more important constraints relate to the possibly boundedly rational nature of cartelists and uncertainty in the market. 
detection based on a proactive cartel policy becomes the only instrument ${ }^{29}$ that allows the combating of cartels outside the logic of the cartel dynamics described by the incentive constraint introduced in Section II. For any given imperfect fining and leniency policy, a subset of markets exists within which the incentive constraint to collude is nonbinding. In such a world, the only remaining possibility for prosecution is a proactive detection policy as provided for instance by the type of market screen methodology outlined in Sections V and VI.

Regarding the second argument, note that cartels that are not deterred by a particular competition policy are characterized by a nonbinding incentive constraint. A change in, for instance, the leniency policy or exogenous market factors, may entail the breakdown of the cartel. Prosecuting latently instable cartels, that is, cartels with a low margin between expected collusive and expected defection profits, indicates low consumer benefits linked to cartel desistence and can therefore not be considered an enforcement priority. ${ }^{30}$ In addition, there seems to be an inherent bias in leniency cartel cases in the sense that cases based on leniency are cartels close to their imminent breakup point: ${ }^{31}$ If market conditions change in a way that renders some cartels unstable, there is a motivation for firms to embellish the ensuing competition by applying for leniency and guaranteeing a reduction in fine for themselves. Clearly, this results in questionable leniency cases, because cartel break-up would have been imminent. In that sense, there is a risk that leniency is little more than terminal care for cartels.

As regards the third argument, it has to be pointed out that deterrence and desistence can be reached through several instruments, including proactive cartel detection. Consider again the incentive constraint determining the internal cartel stability and assume that the constraint is just nonbinding for some industry (that is, collusion is marginally sustainable). The incentive constraint is violated when either the expected profits of collusion (left-hand side of the incentive constraint) are reduced or when expected defection profits

29 Although technically complainants and whistleblowers also belong in this category, these means of triggering an inspection can hardly be considered proactive policy instruments as they are beyond the control of the authority.

30 Note that with high discount factors future (competitive) profits become important, rendering the one-time deviation profit less relevant. In that sense, the incentive constraint is then close to a direct comparison of collusive versus competitive profits. Furthermore, detecting cartels with a high margin between expected collusive and expected defection profits may be considered a priority as the slack in the incentive constraint can be leveraged into adjacent markets. See Bernheim and Whinston (1990).

31 It seems also rather plausible that these will not be recently started cartels but rather cartels in the ending phase given that cartel startup typically involves some fixed costs, rendering cartel formation only profitable if expected collusive profits are substantially above expected defection profits. See Stephan (2006) for an empirical evaluation of the 1996 leniency notice and Goppelsroeder et al. (2007) for a theoretical analysis at what stage of the cartel lifecycle applications for leniency occur. 
(right-hand side of the incentive constraint) are increased. The former can be achieved by an increase in the detection probability and/or an increase in the fine, and the latter by reducing the fine or awarding a reward within a leniency program. ${ }^{32}$ Although not necessarily equivalent, ${ }^{33}$ collusion can thus be discouraged through higher fines and higher detection probability, lowering the expected collusive profits, or through fine reductions or rewards to the defecting firm increasing the expected profits of defection based on leniency. The level of deterrence is therefore a function of fines, detection probability, and leniency. From that perspective, any policy instrument capable of deterrence should play a vital role in the practice of a competition authority. ${ }^{34}$

Finally, it can be argued that proactive cartel detection, besides its intrinsic importance, is also relevant as a complement to leniency. The effectiveness of instruments used to trigger inspections is interrelated in the sense that increased detection through ex officio procedures or solid evidence based on complainants or whistleblowers reinforces deterrence and desistence. Economic market screens in turn have an encouraging effect on complainants and whistleblowers because even cases initially exhibiting weak evidence can be followed up.

From this perspective, it is important to reinforce existing cartel policy by establishing a second leg of enforcement allowing the active detection of cartels outside the logic of the cartel dynamics as described by the incentive constraint. Only with inspections triggered ex officio can the set of cartels in the immediate reach of a competition authority be increased beyond traditional deterrence and desistence.

In the following, the appropriateness of different methods for triggering inspections ex officio will be assessed.

\section{METHODS OF CARTEL DETECTION-TOP-DOWN VS. BOTTOM-UP APPROACHES}

In principle, two main approaches for cartel detection based on economic criteria can be identified in the literature, top-down and bottom-up approaches. Top-down approaches screen several sectors to identify industries

32 This holds under the assumption that defection will in some instances result in prosecution and therefore the imposition of fines.

${ }^{33}$ It is outside the scope of this paper to discuss the likely asymmetric effects of these policies on, for instance, the resources of a competition authority. Clearly instruments are unlikely to be equally feasible and effective under more realistic conditions.

34 An analogy can be drawn to the optimization problem of a multiplant firm. A firm composed of several plants producing the same product but with different (increasing) marginal cost technologies can produce the same output with lower total cost by optimizing the allocation of inputs between the plants: in optimum, the marginal costs of production are equal in all plants. Interpreting the probability of detecting a cartel as "output," the individual policy instruments as "plants," and the competition authority's resources as "input" shows that employing multiple instruments typically forms part of an optimal resource allocation plan for a competition authority in the absence of corner solutions. 
prone to collusion. An example of such a top-down approach can be found in a study carried out by Grout and Sonderegger (2005) for the Office of Fair Trading (OFT) ${ }^{35}$ Grout and Sonderegger use the incidence of cartels detected by EC and U.S. competition authorities as a measure of cartelization of an industry and try to explain the level of cartelization by various industry specific variables (such as industry turnover, cost measures, concentration measures, measures of entry barriers, or volatility measures) through regression analysis. ${ }^{36}$ The regression analysis allows the authors to derive a probability of collusion for industries that have not been suspected of collusion in the past, thereby providing a tool for competition authorities to generally redirect their enforcement priorities.

Although providing helpful insights, top-down methods are often affected by four severe shortcomings. First, the level of aggregation is generally too high to identify specific antitrust markets and, in addition, industry classifications do not match antitrust markets. Top-down methods thereby do not allow identifying a specific market for cartel inspection, but can only indicate suspicious sectors.

Second, an empirical analysis across various sectors requires well-defined, "automated" screens. In principle, those screens can be reengineered if the general approach is known by industry experts or economic consultants, allowing cartels to be designed in such a way as to shield them from detection.

Third, the relationship between economic factors and the probability of collusion is often not linear, for example, the probability for explicit collusion is maximized for an intermediate level of transparency. ${ }^{37}$ Furthermore, different combinations of various economic factors may have different effects, for example, a high level of price parallelism in a highly concentrated industry may be considered as an indicator for a higher probability of collusion while price parallelism in a highly fragmented market matches the theoretical prediction of the behavior of competitive firms.

Fourth, by relying on past cartel detection to predict cartel activity in other industries in the future, a selection bias is introduced if the cartels detected are not a representative sample of cartels in general. If that is the case, enforcement priorities will be biased and will tend to focus on industries comparable to those in which cartel activity was detected. ${ }^{38}$

35 Other examples are NERA (2004) or Lorenz (2005).

36 The regression analysis is based on three-digit (SIC) industry classification; the measure of cartelization is the number of detected cartels in individual industries since 1990 (for EC) and since 1994 (for the United States) until 2005. Various regression methods are applied (OLS, Logit, Probit).

37 See Grout and Sonderegger (2005: 71-3) for a discussion of this point.

38 If leniency-based cartel cases are predominantly about latently instable cartels, any empirical analysis based on such cases will necessarily mirror the properties of these latent instable cartels and therefore mislead the efforts of antitrust enforcers. 
Unlike top-down approaches that are applied to a wide range of sectors or markets, the bottom-up approach focuses on a particular sector or market. ${ }^{39}$ Bottom-up approaches thereby do not rely on cross-sector data; they can adopt a more flexible set of criteria and are therefore less vulnerable to strategic behavior; they can at least partially address the issues of nonlinearity of individual factors by a more case-based approach and they are less affected by the selection bias as additional theoretical considerations can easily be taken into account. Obviously, bottom-up methods have their own problemsmost importantly, the availability of public market data and the resource requirements for implementing such an approach. We will discuss these issues in more detail in the following section.

Overall one has to conclude that, although they may provide some general guidance, top-down methods are unlikely to meet the legal burden needed to justify inspections (see Section III). ${ }^{40}$

The next section outlines a practical bottom-up methodology adapted to the administrative context of a competition authority.

\section{OUTLINE OF A FRAMEWORK FOR INITIATING EX OFFICIO INVESTIGATIONS}

To allow for a flexible and targeted use of the methodology in priority areas or markets that appear suspicious, the initial selection of the sector or market is not part of the framework. It should also be noted that the methodology has a value for the competition authority outside its direct purpose of triggering inspections. As the methodology discusses the economic rationale of cartel formation, it allows a systematic structuring of the investigation. This can be useful in any cartel case, even if inspections are not triggered using the methodology. ${ }^{41}$

The methodology is divided into two steps. The first step, labeled industry analysis, consists of a series of indicators aggregated by a scoring system. The purpose of the industry analysis is to exclude cases where cartel activity is relatively improbable and to allow a first assessment of the merits of a case. If the first step indicates conditions conducive to cartel formation in a particular

39 See also NERA (2004: 176-217) and Friederiszick and Maier-Rigaud (2007) for an attempt along these lines.

40 Grout and Sonderegger (2005) identify, for instance, "telecommunications," "manufacture of aircraft and spacecraft," and "manufacturing of grain mill products, starches and starch products" as three of the sectors most probable for collusion but where yet cartels have not been detected (see p. 8 for a complete ranking). A simple screening based on Herfindahl indices would have potentially led to comparable rankings; the broadness of the classification "telecommunications" shows the coarseness of the methodology.

41 For instance, an early understanding of the cartel logic may allow streamlining of the cartel procedure by asking the right economic questions to leniency applicants, informants, and whistleblowers or by allowing better targeted inspections (that is, scrutiny of particular dates surrounding critical events, for instance). 
market, the framework foresees a second step consisting of a critical event analysis, where key issues identified in the industry analysis are tested in a more rigorous way. The second step aims at establishing a reasonable theory of harm and to test this theory by a focused in-depth analysis of events of particular relevance for the case under investigation. ${ }^{42}$ Both steps together allow an economically informed decision as to whether to carry out an inspection or not. ${ }^{43}$

\section{A. Step I: Industry Analysis}

The scoring exercise is supposed to filter out cases where cartel activity is unlikely. It addresses factors typically considered necessary for collusion. Below we will provide a list of indicators considered relevant in line with the broad literature on collusion-facilitating factors. ${ }^{44}$ It is important, though, to recognize that the industry analysis goes beyond a simple checklist approach, thereby providing the conceptual grounds for carrying out the second step of the framework.

First, the industry analysis starts with a preliminary market definition and an identification of the main suspects, typically including the largest firms. It is only within the boundaries of an antitrust market that a collusive agreement can become effective. A reasonable but simple starting point for proper market definition can be, for instance, a recent merger decision. It has to be noted that the definition of the relevant market may change during the course of the industry analysis, that is, submarkets may be identified with considerably different competition conditions. In such a case, which will be the rule rather than the exception, the assessment of the individual indicators has to be redone in its entirety for the newly defined antitrust market.

Second, the industry analysis requires the definition of a reference period and within that period a critical time window where cartel activity is suspected. Defining a critical time window allows checking for substantial changes (compared with other time periods) in factors determining the functioning of markets. ${ }^{45}$ For instance, it is difficult (and industry-dependent) to judge whether the stability of market shares indicates collusive behavior or not. If market shares are more stable during the critical time window than during

42 One way to interpret the approach is that the industry analysis is concerned with false negatives, that is, it minimizes the probability of overlooking existing cartels. The question of false positives, namely, the case where a situation is caught by the industry analysis but no competition problem exists is dealt with in the second step.

${ }^{43}$ Note, however, that the two steps of the test are not independent in a statistical sense.

44 There is general consensus between economists on what factors facilitate collusion. Discrepancies mostly exist regarding the weights put on specific factors by individual authors. See, for instance, Scherer and Ross (1990), Grout and Sonderegger (2005: 18-36), NERA (2004: 175-216), and Connor (2007: 32-42).

$45 \mathrm{See}$, for instance, Harrington (2005) or Porter (2005) for the importance of changes in the relevant factor for cartel detection. 
other periods in the observation period, this is evidence for a 'structural break' in the factors determining the functioning of the market. One possible explanation for such a structural break is the establishment of a cartel. Just as with the definition of the relevant antitrust market, the critical window may be readjusted over the course of the industry analysis. The readjustments are made so that the critical time window reflects periods of structural breaks that cannot be easily explained by other, noncollusive factors.

A further element to be considered when looking at the indicators proposed in the literature is that all collusion-facilitating factors are informative but none of them is by itself sufficient to trigger an inspection nor a critical event analysis because they may well be in line with a competitive market situation. Hence, a scoring exercise that involves determining the relative importance of each indicator is necessary. Ideally, such an exercise would take into account (1) the importance of individual or groups of indicators, (2) the interdependency of indicators, (3) the reliability of the information, and (4) quantitative versus qualitative data.

\section{The Importance of Individual Indicators}

The purpose of the scoring exercise is to account for the relative importance of different factors. For instance, product homogeneity may be less important than the existence of facilitating practices such as public price announcements. The distinction between primary and secondary indicators follows the logic that some indicators are deemed essential ingredients for collusive behavior and are therefore considered to be more important for identifying a cartel than others. The scoring at the end of the first step takes these differences into account by attributing a higher weight to primary indicators than to secondary ones.

\section{Interdependency Between Some Indicators}

The impact of some indicators may depend on the outcome of other indicators. Even more importantly, the direction of the indicator's impact may depend on the existence of other facilitating conditions. For instance, price parallelism may be found in competitive and collusive markets. Hence, the scoring has to consider the interdependency of the indicators. This is also the reason for developing a reasonable theory of harm based on a change in relevant variables in the critical event analysis before an inspection is triggered.

\section{Availability and Reliability of the Information}

As regards the availability of information, the indicators in step one are of a more general nature and should be available through public sources, such as industry reports or official databases. More detailed information should be available through internal sources, such as merger inquiries, state aid investigations, or sector inquiries. By introducing a larger set of indicators than may be considered necessary under ideal conditions, the methodology assures a 
certain robustness against the occasional lack of information. Assessing the reliability of information, in particular if provided by informants, is, however, important. A broader, case-independent framework such as a methodology provides a safeguard against distortions.

\section{Quantitative versus Qualitative Data}

Some data are of quantitative nature (for example, concentration ratios), and others are of qualitative nature (for example, transparency of prices). The scoring should guarantee comparability of quantitative and qualitative information.

Although the relevance of individual indicators is reflected in the methodology by defining primary and secondary indicators, the other features (24) are not explicitly introduced in the scoring methodology. The main reason for not directly incorporating those aspects is that the transparency of the mechanism is important in guaranteeing that it is not misapplied or blindly trusted. Although a mechanical approach is important in applying the indicators at first, a reasonable application of the methodology can only be assured if the approach allows some flexibility.

A key issue in any empirical methodology is how to gather the necessary information without revealing the ongoing scrutiny to cartel members. The proposed methodology partially addresses these concerns by an effort to base the indicators in step one as much as possible on data available through public sources, such as industry reports or official databases.

In the following, we will briefly outline the individual indicators considered to be of relevance. The indicators are related to price development, to the level and type of transparency, to market concentration and entry conditions. Important indicators are considered primary and are given more weight than secondary indicators in the scoring.

Prices are a prominent element of any methodology aimed at detecting collusive behavior. Without change in costs, price increases indicate changes in market power and hence changes in profitability, which is the main reason for any collusive agreement. ${ }^{46}$ Furthermore, prices are often the strategic variable agreed upon under collusive agreements.

Price measures can be based on price changes over time, price changes between the critical time window and the average price, or on measures of price volatility; correlation coefficients can help to control for changes in costs, demand, or capacity utilization; cross regional comparison of price levels or changes can provide further insights. ${ }^{47}$

${ }^{46}$ Given the difficulties in measuring profitability, no direct indicator of profitability has been included in the industry analysis.

${ }^{47}$ It goes beyond the scope of the paper to discuss practical problems of data cleaning, for example, how to incorporate changes in taxes or exchange rate fluctuations in cross section data. See NERA (2004: 162) for some advice on the later issue. 
Transparency, to which the second group of indicators is linked, is usually considered to be an important element to establish and to maintain a collusive agreement. Being true in particular for cases of tacit collusion, it is also important for explicit cartel agreements: In an intransparent market environment, reliable information on a cartel member's behavior is difficult to monitor even if direct communication is feasible. Hence, some level of transparency seems to be a necessary element of both types of collusion. ${ }^{48}$ Observable efforts of market participants to increase transparency are particularly indicative of an increased probability of collusive agreements.

Not all types of transparency or information exchange are considered equally strong indicators for collusive behavior in the economic literature. In principle, information exchange is more indicative of anticompetitive conduct $^{49}$

- when carried out between producers in contrast to information being exchanged between producers and customers;

- when disaggregated information is exchanged, that is, information on individual producers, in contrast to aggregated information;

- when information about prices, costs, or sales is communicated in contrast to information about product characteristics;

- when announcements of future actions (that is, prices) do not involve any commitment towards customers.

Given the rather complex and industry-specific channels through which communication between firms can be established, the indicators have to be rather broadly defined and require a qualitative assessment. Relevant factors for assessment are whether the price structures are simple and product characteristics comparable, making price comparisons between competitors easy; whether industry specific pricing schemes are in place, such as a base point system, a reference good system, a most-favored customer clause, a meeting-competition clause; whether announcements on future prices, planned sales figures, or capacity expansions are made on a regular basis; whether a well-structured industry/trade association exists or whether a significant number of competitors sell their products on common business-to-business market places.

Another cluster of indicators is related to concentration. The probability of a stable collusive agreement is higher in concentrated markets, where the main producers have symmetric market shares and maverick firms are absent.

48 As discussed earlier, it is a medium level of transparency that is particularly conducive to explicit cartel agreements. In a perfectly transparent market environment, firms may prefer to collude tacitly to minimize the probability of detection or punishment by a cartel authority, or simply to minimize transaction costs of cartelization. Therefore, the thresholds for transparency indicators should not be set too high to "catch" those medium transparent cases as well. See Grout and Sonderegger (2005).

49 See Kühn (2001). 
Countervailing buyer power decreases the effectiveness of any collusive agreement. For instance, the concentration ratio of the four main producers is considered an important indicator because evidence of cartels maintained in industries without a small group of ring leaders organizing the cartel is rare. Stable market shares are also considered a key indicator, potentially signaling an effective quota cartel. Other relevant factors are the existence of a maverick firm, limited countervailing buyer power, or high symmetry in market shares.

Last but not least, the existence of entry barriers is inevitable for a collusive agreement to become effective as, in the absence of such barriers, cartel profits will erode due to entry of new competitors. ${ }^{50}$ Typical examples are economies of scale (for instance, due to advertising or R\&D fixed cost) or regulatory barriers (such as a restricted number of available licenses). A commitment of incumbent firms to reserve large excess capacities can deter entry as well. ${ }^{51}$

The existence of entry barriers and the observation of historically low entry and exit rates are indicators for an increased probability of collusion. Occasional entry, however, is not inconsistent with a high probability of (explicit) collusion as collusive agreements often arise in reaction to potential entry.

Low innovation rates in an industry may also be a factor (independent of other entry barriers) because they significantly impact other indicators in support of establishing a collusive environment, in particular transparency.

Two points have to be pointed out. First, several indicators can be assessed quantitatively, such as the change in price volatility or R\&D intensity. Specific thresholds can be defined for those indicators, for example, based on industry averages. Others can only be assessed on a qualitative basis. Such an approach has the advantage of leaving some room for discretion in the assessment, limiting the potential of strategic behavior by potential cartelists. Second, some classical indicators in particular "product homogeneity" have been excluded from the list of indicators (it is only indirectly assessed when assessing transparency). This omission was intended to counter the selection bias inherent to traditional forms of cartel detection described before.

The scoring exercise is supposed to provide guidance on the qualitative analysis that will be described in the following section.

\section{B. Step II: Critical Event Analysis}

The critical event analysis is the second step of the methodology and provides for a twofold change in perspective from the first step. First, the approach

50 The NERA study (2004) provides a list of the different types of entry barriers (p. 7). One may also refer to the EC Merger Guidelines (paragraph 71).

${ }^{51}$ Excess capacity can also be an element in stabilizing a collusive agreement (by retaining the potential to punish deviating cartel members). At the same time, however, it increases the individual incentive to deviate. Given the mixed results from the economic literature on that topic, excess capacity is not considered as an individual indicator increasing the probability of collusion, but only as a potential entry barrier increasing the probability of collusion being feasible. 
moves from an indicator-based relatively mechanic data analysis to an analysis of critical events that may entail either significant changes in the market environment or in the behavior and performance of the alleged cartel members. Second, in addition to this change in the methodology, the focus of the analysis changes from screening a market for criteria conducive to collusion to one that is testing the hypothesis of collusive behavior by systematically checking whether competition is a plausible explanation for the observed behavior. Although the first step aims at collecting as many indications for collusion as possible, the second step is designed to test the hypothesis of collusive behavior against the presumption of functioning competition.

To identify critical events, two questions based on the information collected in the industry analysis have to be addressed: (1) Is it possible to identify exogenous shocks that result in different reactions in a cartelized versus a competitive environment? (2) Is it possible to observe structural breaks that cannot be explained along the lines of a competitive environment? Once the empirical foundations of the critical event have been established, the general test structure proposed foresees a test based on two competing scenarios. The first scenario is based on factors specific to the industry, which could explain the observed behavior as an outcome of a competitive process. The second scenario collects evidence for the behavior to be explained as an outcome of collusion.

The central idea of the test is to establish a proper assessment of the counterfactual, that is, how the markets would be structured but for collusion. It therefore mimics the central concepts of Art. 81 ECT. $^{52}$ The derived scenarios are then put in "a horse race to determine which better fits the data."53

Based on a literature survey, seven critical events have been identified as potential candidates for cartel identification. In the following, we will briefly survey these events.

\section{Critical Events Arising in Particular During Cartel Start-Up}

In principle, the empirical knowledge about what triggers explicit cartel behavior is rather limited despite a high number of successful cartel prosecutions. In some instances, it may be a gradual process of reduced rivalry that turns at some point in time into explicit collusion (changes in management may play a significant role in this process). In those cases, the detection of the starting point of the cartel is rather difficult due to its gradual creation. ${ }^{54}$

In most instances, cartel formation is in response to an erosion of prices and profitability due to external events, such as increased import penetration or

52 See the recent decision by the CFI, O2 vs Commission T-328/03 from May 2, 2006, for the concept of counterfactual analysis under Art. 81 .

53 Harrington (2005: 18).

54 Harrington (2005: 37), for instance, depicts price paths during the start-up of the citric acid cartel. It took roughly two years until prices peaked at their maximum. More recent theoretical work replicates these empirical findings (Harrington and Chen, 2006). 
competition from new products. When prices fall below some critical threshold, market participants may turn to each other to reestablish profitability. Tacit collusion may turn into a closer explicit type of cooperation. It is plausible to assume that a significant structural break arises both in prices and in other observable parameters. Hence, indicators related to the cartel start-up mainly focus on identifying a structural break for relevant parameters on a firm and industry level.

\section{Critical Events Arising in Particular During Cartel Life Span}

During its life span, a cartel is exposed to the problem of internal and external instability. Internal instability refers to the incentives of cartel members to deviate from the cartel price: although joint profits can be maximized by market cartelization, the best response to collusion by all firms is individual defection. External instability refers to the incentives of noncartel members to expand production or enter the market in response to higher cartel prices. In both cases, prices may drop significantly for a limited time.

As regards internal instability, temporary price wars may be needed to stabilize a cartel in an uncertain environment. Cartel members may try to adjust their 'share of the cake' in response to an improved market position. If the incentives of individual cartel members change significantly and on a lasting basis, complete cartel breakdown may be the consequence. Such a significant change in incentives may be triggered, for instance, by a drastic change in firm specific cost, in innovation, capacity, or in management. The decision of a cartel member to sell part of its business may also result in noncooperative behavior to increase the sales price.

External instability is the second threat to a cartel. Depending on the economic strength of the individual firms, reputation effects, and the market environment, accommodation, deterrence, or cartel breakdown may be the consequence. Accommodation describes a strategy where the cartel, eventually after a period of price wars, accepts a new entrant and agrees on a new market sharing rule. Deterrence describes a strategy to fight off the entrant by significant price reductions, often focused on the regional markets of the new entrant. ${ }^{55}$ As a consequence, the entrant may fail to gain a viable market share and may subsequently exit. A permanent reduction of entry barriers may, nevertheless, lead to a steady stream of new entrants, resulting in complete cartel breakdown.

55 In addition to punishment through the market, cartels may exert physical punishment as well. For instance, the first entrant in the New York garbage cartel, a long-lasting cartel between the regional garbage collectors, was welcomed by a severed dog's head in his mailbox holding the notice "Welcome to New York" in its mouth. See http://www.manhattan-institute.org/html/ cb_7.htm. 


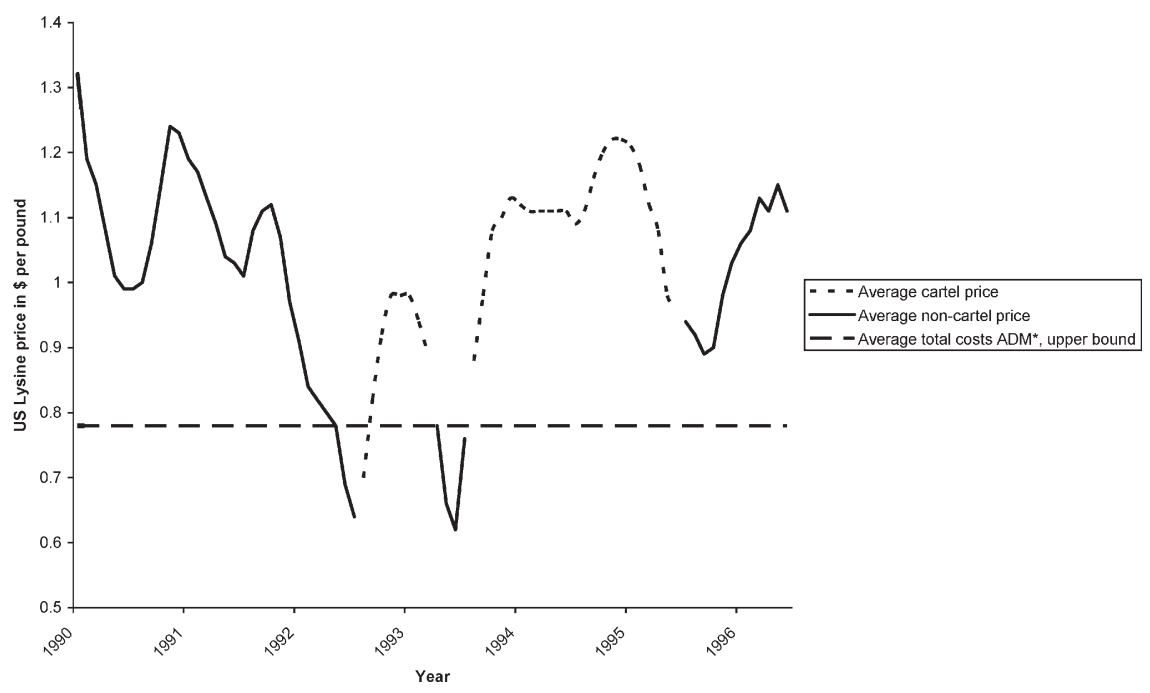

Figure 1. Temporary price wars and accommodation in response to entry in the lysine cartel. Source: based on data provided by Connor (2000:213-15).

The lysine cartel provides a typical example of the effects of entry and subsequent accommodation on cartel prices. ${ }^{56}$ In 1990, two Japanese firms (Ajinomoto and Kyowa) and a South Korean firm (Sewon) were the only large producers of lysine. The Japanese firms had a history of collusion, and from 1986 to 1990 they fixed prices and divided the U.S. lysine market. ADM (a U.S. firm) entered the market in February 1991, and increased its production gradually until it reached roughly 80 percent of the U.S. market and one-third of the global lysine production. By summer 1992, the U.S. prices had dropped by nearly 50 percent. In August 1992, ADM proposed the creation of a trading association that reestablished the earlier cartel, accommodating ADM's market entry. Despite a brief price war during 1993, owing to some internal conflicts, the cartel remained intact until a dawn raid was carried out by U.S. agencies.

In line with this example, one of the critical events identified in the methodology is a temporary but substantial price reduction in an environment of unobservable demand. Further critical events arising during the life span of a cartel and identified by the methodology are a noncompetitive cost-price relationship, parallelism in pricing or output decisions, and price stabilization after entry.

56 Connor (2004) provides a short overview of the case. Bolotova et al. (2005) present results from empirical testing of the hypothesis that prices have increased and price variance has decreased during the cartel. 


\section{Critical Events Arising in Particular During Cartel Breakdown}

Typically, cartels break down due to a substantial change in the market environment-the most important changes are entry, import penetration, innovation (both product innovation and drastic process innovation), or discrete capacity expansion. A permanent cartel breakdown may often be accompanied by a replacement of management. If a cartel breaks down in response to one of these events, the price reduction will be more drastic than it would have been in a competitive environment. Hence, it is the size of the effect that allows one to distinguish between collusive and competitive behavior. In the following, we concentrate on entry as a critical event.

The frozen perch case is a good example of the effect of cartel breakdown on prices (Abrantes-Metz et al., 2006). The cartel rigged bids for frozen seafood sold to the Defense Personnel Support Center (DPSC) in Philadelphia. The collusive practice started in 1981, at first including only two firms; soon after others were included. The colluding firms allocated contracts among themselves, and firms not designated as the winning bidder agreed to submit high bids. Communication was done by telephone. Information on the cartel's total market share during the conspiracy is not available.

In June 1998, one of the firms broke out of the cartel. From mid-July 1988 to late September 1988, prices fell dramatically. This may have been the outcome of a punishment phase, or the result of cartel breakdown. Formally the conspiracy ended in September 1989, due to government investigation. Five firms were prosecuted; all pleaded guilty and were fined. In response to the cartel investigation, prices dropped by roughly 30 percent. The long-term price in the period after cartel breakdown was only 16 percent below the cartel price in this case. In accordance with this example, a significant price decrease after entry is considered a critical event arising during the breakdown of a cartel.

In addition to the discussion of critical events, the main theoretical underpinnings and a list of relevant market-specific factors as well as examples of existing case studies, the methodology foresees the creation of a case library. Such a library may be used to benchmark market behavior and market-specific factors in the case at hand against proven cartel cases. The library will also help case handlers to identify analytical tools applicable to the critical event and provide reference cases providing detailed guidance on how to carry out the analysis.

\section{CONCLUSION}

An economic methodology has never been used by the Commission to justify inspections and the problems inherent in using economic analysis for triggering inspections have to be considered. Three main problems can be identified. First, economic evidence may be interpreted in different, and often contradictory, ways and there is no general agreement as to how collusive markets operate. Certain market features may be interpreted as being in line with both 
collusion and competition. This creates problems for any legal procedure that relies on economic analysis as evidence. The limited insight into how to distinguish between explicit and implicit collusion further aggravates this concern.

Second, issues of data availability and reliability limit the application of economic methods significantly. Micro data of necessary accuracy are often not publicly available. Official requests for information would give away the secrecy of the investigation. By dividing the methodology into two steps, the data requirements are significantly reduced as the data necessary for step one are usually publicly available. Building up a case library to benchmark observed market behavior with past experience further reduces the data requirements for the second step once a significant case library is set up. How far active information gathering tools, such as information requests, may occasionally be useful is left open.

Third, limited resources of a competition authority will limit the scope of active cartel detection by a competition authority and capacity building within a competition authority is of central importance.

Despite these inherent problems of any market screen methodology, we have argued that ex officio cartel screens are a necessary tool for any modern competition authority. As a competition authority that in addition to leniency relies exclusively on whistleblowers and complainants to trigger inspections has neither influence on the frequency nor on the informational and evidentiary quality of input, ex officio cartel screens remain the only viable proactive policy tool for detecting and prosecuting cartels outside the logic of cartel dynamics. Competition policy has to base its effect on the classic passive tools for increasing deterrence and desistence and the proactive tool of detection. The methodology proposed in this paper is considered a first step towards a proactive cartel policy that if implemented will hopefully be capable of striking the balance between passive and active enforcement tools and also streamline the way cartel cases are dealt with.

\section{REFERENCES}

Abrantes-Metz, R.M., Froeb, L.M., Geweke, J.F., Taylor, C.T. 2006. A Variance Screen for Collusion, International fournal of Industrial Organization, 24: 467-86.

Apesteguia, J., Dufwenberg, M., Selten, R. 2007. Blowing the Whistle, Economic Theory, 31, 143-66.

Beckenkamp, M., Hennig-Schmidt, H., Maier-Rigaud, F.P. 2007. Cooperation in Symmetric and Asymmetric Prisoner's Dilemma Games_Experimental Evidence. Bonn: Max Planck Institute.

Bernheim, D., Whinston, M.D. 1990. Multimarket Contact and Collusive Behaviour, Rand fournal of Economics, 21: 1-26.

Binmore, K. 1992. Fun and Games. A Text on Game Theory, Lexington, MA: Heath.

Bolotova, Y., Connor, J.M., Miller, D.J. 2005. The Impact of Collusion on Price Behaviour: Empirical Results from Two Recent Cases. West Lafayette, IN: Purdue University.

Buccirossi, P., Spagnolo, G. 2006. Leniency Policies and Illegal Transactions, fournal of Public Economics, 90: 1281-97. 
Cabral, L.M.B. 2005. Collusion Theory: Where to Go Next?, fournal of Industry, Competition and Trade, 5: 199-206.

Connor, J.M. 2000. Archer Daniels Midland: Price-Fixer to the World, 4th edn. Staff Paper 00-11. West Lafayette, IN: Purdue University.

Connor, J.M. 2004. Global Cartels Redux: The Amino Acid Lysine Antitrust Litigation (1996). In The Antitrust Revolution, 4th edn, J.E. Kwoka, L. White (eds). Oxford: Oxford University Press.

Connor, J.M. 2007. Global Price Fixing. Studies in Industrial Organization, 2nd edn. Berlin: Springer.

Engel, C. 2006. Wettbewerb als sozial erwünschtes Dilemma. In Recht und spontane Ordnung. Festschrift für Ernst-foachim Mestmäcker zum 80. Geburtstag, C. Engel, W. Möschel (eds). Baden-Baden: Nomos-Verlag, pp. 155-98.

Engel, C. 2007. How Much Collusion? A Meta-Analysis on Aligopoly Experiments, fournal of Competition Law and Economics, forthcoming.

European Commission 2006. Report on Competition Policy 2005, available at http://ec.europa.eu/ comm/competition/annual_reports/2005/en.pdf.

Feuerstein, S. 2005. Collusion in Industrial Economics-A Survey, fournal of Industry, Competition and Trade, 5: 163-98.

Friederiszick, H.W., Maier-Rigaud, F.P. 2007. The Role of Economics in Cartel Detection in Europe. In The More Economic Approach in European Competition Law, D. Schmidtchen, M. Albert, S. Voigt (eds). Tübingen: Mohr Siebeck.

Friedman, J.W. 1971. A Non-cooperative Equilibrium for Supergames, Review of Economic Studies, 28: $1-12$.

Goppelsroeder, M., Schinkel, M.P., Tuinstra, J. 2007. Corporate Leniency Programs in the Cartel Lifecycle: "Cleaning out the Closet", ACLE working paper.

Green, E.J., Porter, R.H. 1984. Non-cooperative Collusion under Imperfect Price Information, Econometrica, 52: 87-100.

Grout, P.A., Sonderegger, S. 2005. Predicting Cartels. Economic discussion paper 773, OFT.

Harrington, J.E. 2005. Detecting Cartels. In Handbook of Antitrust Economics, P. Buccirossi (ed.). Cambridge, MA: MIT Press (forthcoming 2008).

Harrington, J.E., Chen, J. 2006. Cartel Pricing Dynamics with Cost Variability and Endogenous Buyer Detection, International fournal of Industrial Organization, 24(6), 1185-212.

Holt, C.A. 1995. Industrial Organization: A Survey of Laboratory Research. In Handbook of Experimental Economics, Kagel, J.H., Roth, A.E. (eds). Princeton University Press: Princeton, pp. 349-443.

Huck, S., Normann, H.-T., Oechssler, J. 2004. Two are Few and Four are Many: Number Effects in Experimental Oligopolies, fournal of Economic Behavior and Organization, 53: 435-46.

Ivaldi, M., Jullien, B., Rey, P., Seabright, P., Tirole, J. 2006. The Economics of Horizontal Mergers: Unilateral and Coordinated effects, $158 \mathrm{pp}$, Luxembourg.

Kühn, K.-U. 2001. Fighting Collusion by Regulating Communication between Firms, Economic Policy, 16(32): 167-204.

Kühn, K.-U. 2005. Collusion Theory in Search of Robust Themes: A Comment on Switgard Feuerstein's Survey, fournal of Industry, Competition and Trade, 5: 207-15.

Lorenz, C. 2005. Screening markets for cartel detection-collusive marker in the CFD cartelaudit, Industrial Organization 0511003, EconWPA.

Luce, R.D., Raiffa, H. 1957. Games and Decisions-Introduction and Critical Survey. New York: Wiley.

Mehta, K. 2005. Comments on Switgard Feuerstein's "Collusion in Industrial EconomicsA Survey," fournal of Industry, Competition and Trade, 5: 217-22.

Motta, M. 2004. Competition Policy: Theory and Practice. Cambridge: Cambridge University Press. 
Motta, M., Polo, M. 1999. Leniency Programs and Competition Policy. European University Institute, Florence, mimeo.

Motta, M., Polo, M. 2003. Leniency Programs and Cartel prosecution. International fournal of Industrial Organization, 21: 347-97.

NERA. 2004. Empirical Indicators for Market Investigations, Economic discussion paper 749, OFT.

Osborne, M., Rubinstein, A. 1994. A Course in Game Theory. Cambridge, MA: MIT Press.

Porter, R.H. 2005. Detecting Collusion, Review of Industrial Organization, 26(2): 147-67.

Rappoport, A., Chammah, A.M. 1966. Prisoner's Dilemma. Ann Arbor, MI: University of Michigan Press.

Riley, A. 2005. Beyond leniency: Enhancing Enforcement in EC Antitrust Law, World Competition, 28(3): $377-400$.

Schelling, T. 1960. The Strategy of Conflict. Cambridge, MA: Harvard University Press.

Scherer, F.M., Ross, D. 1990. Industrial Market Structure and Economic Performance, 3rd edn. London: Houghton Mifflin.

Selten, R. 1973. A Simple Model of Imperfect Competition where Four are Few and Six are Many, International fournal of Game Theory, 2: 141-201.

Shapiro, C. 1989. Theories of Oligopolistic Behaviour. In Handbook of Industrial Organization, Schmalensee, R., Willig R.D. (eds). Amsterdam: North Holland, Vol. 1, pp. 329-414.

Stephan, A. 2006. An Empirical Assessment of the 1996 Leniency Notice, CCP Working Paper $05-10$

Tirole, J. 1988. The Theory of Industrial Organization. Cambridge, MA: MIT Press.

Walker, V.R. 2006. Search for a competition metric: the role of testimony from customers, competitors and economists, Competition Law International, April: 3-7. 